
\title{
25 Research Square \\ Epidemiological Profile of Decision Making Competent Adolescents Engaged in Mental Health Therapy
}

E. Tsamadou

Aristotle University of Thessaloniki School of Medicine: Aristoteleio Panepistemio Thessalonikes

Tmema latrikes

Polychronis Voultsos ( $\sim$ pvoultsos@auth.gr)

Aristotle University of Thessaloniki School of Medicine: Aristoteleio Panepistemio Thessalonikes

Tmema latrikes https://orcid.org/0000-0003-1446-0705

\section{A. Emmanouilidis}

Institute of Mental Health

E. Demertzi

Institute of Mental Health

\section{G. Ampatzoglou}

Aristotle University of Thessaloniki Department of Medicine: Aristoteleio Panepistemio Thessalonikes

Tmema latrikes

\section{Primary research}

Keywords: Adolescent(s), Decision Making Competent / Competence, Epidemiological profile, Engagement in Psychotherapy

Posted Date: March 11th, 2021

DOl: https://doi.org/10.21203/rs.3.rs-276315/v1

License: (c) (i) This work is licensed under a Creative Commons Attribution 4.0 International License.

Read Full License 


\section{Abstract}

Background: A subset of adolescents with mental disorders maintain their ability to be fully engaged in shared clinical decision making process in the context of their psychiatric treatment engagement, thereby promoting an effective therapeutic process.

Aim: This paper aims at exploring the epidemiological profile of adolescents who are already engaged in mental health treatment while maintaining their ability to be fully engaged in shared decision making process.

Method: A single-center cross-sectional cohort survey was conducted. A sample of fifty participants recruited from Child and Adolescent Psychiatry outpatient setting of a tertiary hospital of Thessaloniki, the second largest city in Greece. An intelligence test (Wechsler Intelligence Scale for Children, WISC III) and a self-report measure of depression (Beck Depression Inventory, BDI II), in combination with a clinical assessment of participants' practical wisdom. The mental disorders were defined and diagnosed using the ICD-10 (1992) (International Classification of Diseases), which is under a process of revision and the new edition of IDC-11 is expected to be put in effect in January 2022. At present, the last edition of ICD-10 is in use since 1992.

Results: The largest percentage of adolescents (44,9\%) were found to suffer from mood (affective) disorders, while $20,4 \%$ suffered from neurotic disorders. We also found pessimism (32,7\%), reduction of energy $(28,6 \%)$ and difficulty in concentration $(32,7 \%)$ in high frequency. $22,4 \%$ of adolescents complained of sleep disorders. For the most part, the findings of our study were consistent with prior studies. However, a limited interest in sex was noted, a fact coming in contrast with international and Greek data, where interest and experimentation around sex seems to preoccupy an essential percentage of adolescents. Furthermore, sleep disorders, either as a symptom of an underlying disease, or as an independent clinical condition, seem to preoccupy adolescents and this may be a motive for their treatment engagement.

Conclusion: For the most part, the findings enhanced prior studies which, however, did not exclusively include decision competent adolescents with mental disorders who were engaged in psychotherapy (for at least two months). Interestingly, however, we identified some nuances related to interest in sex and sleep disorders. Further research is recommended for the investigation of possible correlations between the lack of interest in sex or sleep disorders and the fact that the adolescents of our sample were decision making competent and engaged in psychotherapy.

\section{Background}

Mental disorders are various. Worldwide scientific collaboration has provided clinical descriptions and diagnostic guidelines, thus developing a Classification of Mental and Behavioural Disorders (i.e. ICD-10 (1992) which, however require revision due to the ongoing "scientific progress and experience". The new edition of ICD-11 is expected to be put in effect in January 2022. At present, the last edition of ICD-10 is in 
use since 1992 [1]. Mentally ill persons do no way lack decision-making competence only for the reason they are mentally disordered [2,3]. Perfect cognitive functions are not necessarily requirements for decision-making capacity (DMC) [4]. Furthermore, (perfect) cognitive functions are not always sufficient for having full DMC. Values, preferences and emotions play an important role in the decision-making process [5]. Modern theorists place considerable weight on values and emotions rather than on cognitive functions when considering one's DMC.

Adolescence is defined as a transitional phase between ages 10 and 19 [6]. Note, however, that adolescence is a culturally defined concept without clear-cut starting (and ending) point [7].

It is widely accepted that a subset of adolescents are capable to consent to medical treatments in specific contexts $[8,9]$. Not surprisingly, the rights of adolescents to be involved in treatment decisions have been expanded in recent years [10]. Adolescents should be involved in treatment decisions to the extent possible $[11,12]$.

Adolescents' involvement in medical decisions has proved beneficial to them as it helps them become better decision-makers in the future [12] and learn that they are beings of 'moral worth' [13]. However, it is impossible to define a cut-off point of consent for medical treatment based on neuroscience [14]. Moreover, the existing consent frameworks do not specify a minimum age for which an adolescent might be considered competent to consent to medical treatment [15-18]. As a consequence, adolescents' decision-making competence should be assessed on an individual case. There is variance in adolescents' decision-making competence. A variety of factors affect adolescents' decision making competence [14]. Besides, it is context-dependent and changes over time [14]. It should be highlighted that there are considerable individual differences in rates of developmental maturation among adolescents [19]. Importantly, little is known about the capacity of adolescents with psychiatric mental disorders to consent to treatment [10].

Approximately $20 \%$ of adolescents experience a mental health problem, most commonly depression or anxiety [20]. Mental health problems increased in adolescents and young adults in Europe between 1950 and 1990, and the cause is largely unknown [21]. The literature on the prevalence of mental disorders among children and adolescents in the general population has significantly increased over the last years [22,23]. Most mental disorders start during childhood, adolescence and early adulthood [24]. Rates of diagnoses have increased substantially [25]. Adolescent mental health problems are an increasing public health issue. Globally, mental (and substance use) disorders are the leading cause of disability in young people [26]. Laufer [27] states that it is difficult to define mental disorders in adolescence and there is a controversy over the topic.

Shared decision-making (SDM) is a part of good medical practice. In the context of SDM physicians should balance the complexities of patient's autonomy (especially the values, preferences and emotions of the patient) with the benefits and risks of the recommended treatment. SDM 'is increasingly being suggested as an integral part of mental health provision' [28], and is particularly so in the context of children and adolescents psychiatry [29]. 
Creating an optimum collaborative working involvement between therapist and adolescent is crucial to achieve a successful treatment engagement [19]. Treatment engagement is decisive in forming an effective therapeutic process and 'may be particularly relevant early in treatment [30]. It is arguably stated that 'attrition in youth outpatient mental health clinics ranges from 30 to $70 \%$ and often occurs early in treatment [30].

In short, a subset of adolescents with mental disorders maintain their ability to be fully engaged in shared clinical decision making process in the context of their psychiatric treatment engagement, thereby promoting an effective therapeutic process. We aimed at exploring the epidemiological profile of adolescents with mental disorders who however maintain their ability to be fully engaged in shared decision making process, and hence, to most effectively improve their treatment engagement.

To our knowledge little has been written about this topic. Our ambition is to contribute to addressing questions about prevention and treatment service planning and therapists training, as well as to inform the design of future studies.

\section{Methods}

A single-center cross-sectional cohort survey was conducted. This study along with another (entitled: Selfperceived barriers to and facilitators of voluntary health care treatment engagement among adolescent outpatients) were parts of a broader research project exploring the topic of consensual mental health treatment engagement among adolescents.

A face-to-face sample survey of 50 adolescents with mental disorders aged 13-18 years was conducted. A total of 50 adolescents (aged 13-18 years, mean $=14,8, S D s=1,616$ ) with psychiatric disorders engaged in outpatient mental health setting (Child and Adolescents Psychiatry department, tertial referral hospital Hippokratio of Thessaloniki, the second largest city in Greece) participated in the study. The study was conducted from June 2016 to December 2019.

\section{Ethical considerations}

The authors obtained adolescent consent and parental consent for adolescent participants. If adolescents and their parents were willing to participate they were given adequate information about the design, purpose, nature and confidentiality of the study, including that participation was voluntary and that consent could be withdrawn at any time during the course of the study. Verbal informed consent to participate was then obtained from each participant and his or her parent(s) prior to participating in this study and documented in recording at the time of the interviews. Anonymity and confidentiality have been maintained throughout the study.

The participants' anonymity was preserved. Their data were stored in a strictly confidential fashion. The study and consent procedure was approved by ethics committee affiliated to Aristotle University of 


\section{Statisticalanalysismethod}

The SPSS statistical package was used for the processing of data. Initially, the quantitive variables were examined for their normality and the existence of outliers. The normality of distribution was examined through the histogram and the Kolmogorov-Smirnov and Shapiro-Wilk tests for the variables of Age, WISC and BDI. The boxplot was used for the tracing of outliers. The Mann-Whitney test was applied with sex as an independent variable and the scores of Age, WISC and BDI as dependent variables.

The binomial test was applied for checking a statistically significant deviation in the distribution regarding sex. For the investigation of correlations between the variables Age, Total WISC score and Total BDI score, Spearman's rank correlation coefficient was used. For the investigation of the frequency distribution of the BDI questions, chi-square goodness-of-fit test was applied. The Kruskal-Wallis test was used for checking if the median scores per adolescence period subcategory demonstrated statistically significant differences.

\section{Results}

Both the histograms picture and the test results refer to non-normal distribution for the variables of Age (Kolmogorov-Smirnov: $p<0,05$. Shapiro-Wilk: $p<0,01$ ), WISC (Kolmogorov-Smirnov: $p<0,01$. ShapiroWilk: $p<0,01$ ) and BDI (Kolmogorov-Smirnov: $p<0,05$. Shapiro-Wilk: $p<0,01$ ). Boxplots revealed the existence of outliers for the variables of WISC (case 21, score 41) and BDI (case 46, score 55). Although it is recommended in statistics to delete outliers, it was decided to maintain them in the present study due to their clinical value. Taking into consideration the above data about non-normal distribution and the existence of outliers, non-parametric tests were applied.

During the exploratory analysis, it was examined whether the answers of the participants were differentiated in regard to the characteristic of sex. For this purpose, the Mann-Whitney test was applied with sex as an independent variable and the scores of Age, WISC and BDI as dependent ones [see Table 1, Additional File 1].

The results showed that for all three variables there were no statistically significant differences between boys and girls in their answers: $\underline{\mathrm{Age}} \mathrm{U}=273,00$. exact $p=0,67, \underline{\text { WISC }} \mathrm{U}=183,50$. exact $p=0,15, \mathrm{BDI} \mathrm{U}=$ 214,00 . exact $p=0,23$. Therefore, the processing included the total of data.

\section{Research of diagnosis}

In total 50 children and adolescents with a mean age of 15 years participated in the study. $42,9 \%$ of participants were boys and $57,1 \%$ girls. The application of Binomial test demonstrated that the deviation in distribution was not statistically significant (exact $p=0,39$ ). The mean WISC score of the participants 
was 95 points and the mean BDI score was 17,7 [see Table 1, Additional File 1]. In table 2 [Additional File 1], we present in detail the mean scores and standard deviations of each BDI question. The highest mean scores were observed in the questions "Change of sleep" and "Difficulty of concentration", while the lowest ones in the questions "Loss of interest in sex" and "Suicidal ideas".

In regard to the total BDI score, we considered a score of 17 as the differentiating point of depressive mood, taking into consideration the proposal of Yannakou et al (2013). In the present research, 23 out of $47 \mathrm{BDI}$ participants had a total score of 17 and above.

\section{Distribution of diagnosis (diagnosis-related groups):}

$44,9 \%$ in the F30-F39 category, [manic episode, bipolar affectional disorder, depressive episode, recurrent depressive disorder, persistent mood disorders(cyclothymia, dysthymia), other mood disorders (ICD-10)] [see distribution of diagnosis, Diagram 1, Additional File 2].

$20,4 \%$ in the F40-F48 category, [neurotic and somatoform disorders, such as phobic anxiety disorder, anxiety disorders, obsessive-compulsive disorder, adjustment disorders, dissociative disorders]

10,2\% in the F50-F59 category, [eating disorders, sleep disorders, sexual dysfunction, substance abuse. Importantly, this category includes anorexia nervosa]

2\% in the F60-F69 and F70-F79 categories, [personality disorders and mental retardation respectively].

$10,2 \%$ in the F80-F89 category, [developmental disorders of speech and language, disorders of scholastic skills and pervasive developmental disorders].

4,1\% in the F90-F99 category, [hyperkinetic disorders, conduct disorders, emotional disorders with onset specific to childhood, tic disorders, disorders of social functioning with onset specific to childhood].

$6,1 \%$ in the Double Diagnosis category

Sleep disorders also scored high in the group through the BDI $(22,4 \%)$

\section{Frequency distribution ofBDI questions}

In the present unit, chi-square goodness-of-fit test was applied. The goal was to investigate whether the participants choose a score with the same frequency in each BDI question or whether they differentiate [see Table 3, Additional File 1] ${ }^{1}$. As Table 2 [Additional File 1] portrays, the participants differentiated as to their answers, except for questions "Reduction of energy, Change of sleep, Difficulty of concentration", where answers were distributed with more uniformity. In general, participants tended to select the first two scores, which refer to lack or less gravity of symptoms. Selection of increased scores, referring to more grave symptoms was noted in questions "Pessimism, Reduction of energy, Difficulty of concentration". 
In the last question referring to loss of interest in sex, the number of unanswered elements rises to $22,4 \%$ and it is the highest compared to the rest of the questions (38 people versus 45 or 46 ). Thirty adolescents $(61,2 \%)$ selected the answer "I have not noticed any recent change in my interest in sex", 3 adolescents $(6,1 \%)$ were less interested in sex than they used to be, 2 adolescents $(4,1 \%)$ had almost no interest in sex and 3 adolescents $(6,1 \%)$ had lost interest in sex completely.

The vast majority of answers sums to the first score selection referring to answer "I have not noticed any recent change in my interest in sex", which corresponds to score 0 . Quite some youth in the group we studied have no sexual intercourse.

Among the BDI questions, only in question 12 (Loss of interest) there was noted a statistically significant difference (early: 18,36 , middle: 22,83 , late: $31,32, \chi^{2}(2)=6,99, p<0,05$ ).

In regard to sleep disorders in our sample, in the analytical form, the answers of BDI question 16 (Change of sleep) were distributed as follows:

I sleep as well as usual (0): $11(22,4 \%)$

I sleep a little more than usual (1a): 9 (18,4\%)

I sleep a little less than usual (1b): $10(20,4 \%)$

I sleep much more than usual (2a): 5 (10,2\%)

I sleep much less than usual (2b): 5 (10,2\%)

I sleep most hours of the day (3a): 1 (2,0 \%)

I wake up 1-2 hours early and can't go back to sleep (3b): $5(10,2 \%)$

\section{Adolescence categories}

For the investigation of a potential correlation between the adolescence period with the intelligence level and the BDI score, participants were divided in three categories: early adolescence (10-13 years), middle adolescence (14-17 years) and late adolescence (17-21 years). Fourteen of the participants belonged to the first category, 24 in the second and 12 in the third. See distribution of diagnosis in boys and girls in Diagrams (Pie Charts) 2 and 3, respectively [Additional File 2].

Afterwards, the non-parametric Kruskal-Wallis test was applied with the adolescence stage as independent variable and WISC and BDI scores as dependant variables.

\section{WISCandBDI scores}


The application of Kruskal-Wallis test showed that the median scores in each subcategory do not differ to a statistically significant degree in regard to the scoring of the participants in the WISC test (early: 20,68, middle: 21,89 , late: $29,33, \chi^{2}(2)=2,70, p=0,26$ ) and in the BDI (early: 23,92 , middle: 23,46 , late: 25,23 , $\left.\chi^{2}(2)=0,13, p=0,94\right)$. Among the sub-questions of the BDI, a statistically significant difference was observed only in question 12 (Loss of interest) (early: 18,36, middle: 22,83 , late: $31,32, \chi^{2}(2)=6,99, p<$ $0,05)$.

In conlusion, the participants did not differentiate as to their WISC and BDI scores in regard to the adolescence stage they were going through (early, middle, late). There is, however, the exception of the sub-question "Loss of interest", where the highest scores were observed in late adolescence, while the lowest on33es in early adolescence.

\section{Summary presentation o results}

Diagnosis distribution: $44,9 \%$ in the F30-F39 category, $20,4 \%$ in the F40-F48 category, $10,2 \%$ in the F50F59 category, 2\% in the F60-F69 and F70-F79 categories, 10,2\% in the F80-F89 category, 4,1\% in the F90F99 category, $6,1 \%$ in the Double Diagnosis category. No differentiation in regard to sex was observed. We found a similar number of boys and girls, mean WISC score of the participants: 95 points, mean BDI score of the participants:17,7. Higher BDI mean scores were noted in the questions "Changes in sleep" and "Difficulty in concentration", while lower BDI mean scores were noted in the questions "Loss of interest in sex" and "Suicidal thoughts". 23 out of 47 BDI participants had a total score of 17 and more. In the questions Pessimism, Reduction of energy and Difficulty in concentration, we observed an increased selection of scores that indicate more grave symptoms. In the question of Loss of interest in sex, , the number of unanswered elements was $22,4 \%$, that is the highest in comparison to the other questions (38 people versus 45 or 46 ). The vast majority of participants selected the first score choice. No correlations were observed among the variables Age of participants, WISC and BDI. The participants did not differentiate as to their WISC and BDI scores with regard to their adolescence stage (early, middle, late). The only exception was the sub-question of Loss of interest, where the highest scores were noted in late adolescence and the lowest ones in early adolescence.

\section{Discussion}

The sample of our study is consisted of fifty adolescents with mental disorders who, however, are decision making competent and therefore they appear "ordinary" adolescents, being capable of taking part in shared decision making process. The largest percentage of diagnosis $(44,9 \%)$ refers to mood disorders (F30-F39). In this category, the change of mood is dominant, either towards depression, or towards euphoria. The change of mood usually is accompanied by a change in the level of general activity and it seems that in our study group as well, the changes in everyday life (sleep, concentration, pessimism) maybe motivate to seeking of assistance, as the increased scores of the above BDI questions reveal. Recent evidence suggests association between urbanization and mood disorders [33]. The high 
prevalence of mood disorders among adolescents may be partly explained by the urbanization model that has been developed in Greece over the last decades. Furthermore, over recent years, Greece has adopted extreme austerity measures that have led to changes in the social landscape. "The economic crisis that hit Italy has posed threats to Italians' mental health and wellbeing" [34]. "Regarding financial distress, it was found to bear a statistically significant association with major depression but not with generalized anxiety disorder" [35]. the fact that mood disorders among adolescents were found in high prevalence may be partly explained by the recent Greek economic crisis which may be an underlying driving factor. At any rate, it is crucial to bear in mind that "social and cultural factors may influence emergence of mental health problems" [36].

In the F30-F39 category, girls outmatch in the appearance of mood disorders. In international studies, it was found that between years 1987 and 1999 adolescent girls presented an increase in psychological stress [37]. Females are more likely to develop mood disorders, a fact confirmed by both our results in this study group as well as by international studies [38, 39]. A systematic review published in 2014 found that the majority of studies report an increase in internalizing problems in adolescent girls [36].

$20,4 \%$ of participants had a F40-F48 diagnosis (neurotic disorders). In this category as well, girls with $14,3 \%$ compared to boys with $6,1 \%$, develop these specific disorders in a higher percentage and specifically, the phobic disorders and the panic disorders with a 2:1 to 3:1 ratio. For some unspecified till now reason, girls appear to be more vulnerable in the development of disorders of neurotic type. "The symptoms of neurotic disorders were more strongly expressed and more common in girls" [40].

The forms of non-manageable stress during adolescence are the same with the ones appearing in the other stages of life: stress attack (panic), generalized anxiety (diffuse feeling of anxiety) with mental disorders characterized by a condition of tension and fear, often accompanied by sleep disorders. Anxiety (agoraphobia, social phobia, school phobia) is accompanied by an undefined sense of restlessness. Anxiety attacks usually start during adolescence and may be accompanied by difficulty in decision making or by somatization [41]. Overall, anxiety disorders and depressive disorders are strongly related, likely share common etiological determinants, and have distinct temporal associations [42]. Comorbid depression and anxiety disorders occur in up to $25 \%$ of general practice patients [43]. Anxious depression (comorbid anxiety and depression) is relatively a common syndrome [44].

$10,2 \%$ ( $8,2 \%$ girls, $2 \%$ boys) belonged to the F50-F59 category, which includes eating disorders, sleep disorders, sexual dysfunction, substance abuse. Anorexia nervosa contains threats for life itself, if not treated in time. The modern beauty models, the search for the "perfect" body image, the dysfunctional family relations usually entrap young girls into restricting their diet and without a timely intervention, the clinical and physical condition rapidly deteriorates. It is calculated that $40 \%$ of anorexia nervosa cases will develop between 15 and 19 years of age. In much lower frequency it appears for the first time in women in their late youth or in middle age [45,46]. A study regarding the period 2013-2014 reported that $31.6 \%$ of Australian adolescents experienced disordered eating [47]. A meta-analysis of 41 studies 
showed increase in prevalence of eating disorders (3.7\% vs. 1.8\%) [48]. Eating disorders are some of the most prevalent disorders in adolescence which moreover, continue to increase [49].

Sleep disorders, which noted high score in the study group, according to the BDI $(22,4 \%)$ is a symptom that can be attributed to an underlying mental disorder, if it is not caused by physical factors. Bad sleep quality affects next day functioning and may particularly bother adolescents, that's why seeking help for its solution may usually be a personal request by the adolescent and not just by the family. Chronic sleep disorders are considered a common condition among adolescents. There has been awareness in the recent years concerning the quality of sleep and mental health. Research shows that girls present with more frequent insomnia than boys [41], [50]. Sleep problems refer to the quantity and quality of sleep in adolescents, difficulties in the coming of sleep, day drowsiness, sleep that doesn't bring rest [51]. Bad sleep quality has been found to relate to mental health problems.

There may be co-occurrence and association between mental health symptoms and sleep problems. It has been estimated that in around $67 \%$ of adolescents with sleep concerns there is co-occurrence of mental health problems in almost similar rates in pre-school and school age groups [52]. Furthermore, Hysing at al. (2016) state that sleep problems may be associated with poor academic performance [53]. Moreover, Zhang et al. (2018) found that "sleep disturbance had significant mediating effects on the relationship between intrafamily conflict and mental health problems in Chinese adolescents" [54].

As regards sexuality, while the vast majority of the participants in our study were very interesting in improving their social and communicative skills and acceptance by peers, they did not show any interest in sex and sexuality. It is argued that "conscious sexual identities, motivations and desires" are present during early and middle adolescence [55]. Low and moderate levels of compulsive sexual behavior are considered part of the normal development of sexuality among adolescents [56]. However, adolescent sexuality is considered "tentative, experimental, confused, inept, and innately dangerous" [57] and cleanly demarcated from adult sexuality [58]. "Adolescence is a crucial period for emerging sexual orientation and gender identity..." [59].

The findings of our survey were inconsistent with a Greek study (Adolescent Health Unit, 2007) which found that in the entire metropolitan area of Athens $20 \%$ of adolescents had already initiated sexual activity before the age of 16 years [60]. This may be partly explained by the fact that the participants in our study were adolescents with mental disorders who, however, were decision making competent. Note, however, that $10,2 \%$ of the participants in our study were adolescents with autism spectrum disorders where there are difficulties in approaching the opposite gender [61]. Furthermore, it is noteworthy that "due to the core symptoms of the disorder spectrum"...some autism spectrum disorder individuals might "develop quantitatively above-average or nonnormative sexual behaviors and interests" [62]. Moreover, the fact that $44,9 \%$ of the participants in our study were adolescents with mood disorders and the high prevalence of pessimism / negativity (36.7\%), reduced activity (30.6\%) and concentration deficit (28.6\%) may partly provide some explanation to the lack of interest in sex and sexuality among the participants in our study. 
$2 \%$ ( $2 \%$ girls, $0 \%$ boys) belonged to the F60-F69 category (personality disorders, gender identity disorders). The specific disorders and especially borderline personality disorders (F60.3) are characterized by extreme behavioral models with serious deviations from average in relating and interacting with others. In our study group, girls were the ones presenting with personality disorders and specifically borderline personality disorder, where instability and fluidity in interpersonal relations is characteristic and it is accompanied by emotional instability, discomfort and compulsive suicide attempts. This may partly explain the low prevalence of adolescents with (borderline) personality disorder among members of a sample consisted of decision making competent adolescents.

The low percentage in diagnosing personality disorders (PD) in our group complies with international data, as personality disorders are set as diagnosis usually in adult life, because of the constantly evolving and changing of personality in adolescence. According to ICD-10, the diagnosis of personality disorders is rather improbable in children younger than 16-17 years, while according to DSM-IV, the diagnosis may be valid in children and adolescents, when specific dysfunctional patterns are pervasive, last for at least one year and are not explained by another psychiatric disorder. Although in adolescents, dysfunctional behavioral models are acknowledged, these are described as peculiar developmental patterns and not as disorders [63] [37]. Feenstra and Hutsebaut (2014) state: "Clinicians seem hesitant about diagnosing personality disorders in adolescents. Furthermore, little is known about the assessment and treatment of adolescents with personality disorders" and "There appear to be more similarities than differences between personality disorders in adolescents and adults" [64]. Moreover, we found higher prevalence of personality disorders in boys. However, as regards borderline personality disorders there is still no clear difference between men and women. Schulte Holthausen and Habel (2018) state: "Hence, despite the number of studies in borderline PD, sex-specific aspects have not been addressed sufficiently and it is still inconclusive to what extent prevalence differences as well differences in symptoms occur between the sexes" [65].

$2 \%$ presented with mental retardation, $\mathrm{F} 70-\mathrm{F} 79$ ( $10,2 \%$ boys, $0 \%$ girls). Mental retardation is condition of retarded development of intellect with incomplete development both of social skills and linguistic and motor skills and it is distinguished in mild, moderate, severe and profound, depending on the gravity of difficulties. This may partly explain the low prevalence of adolescents with (mild) mental retardation among members of a sample consisted of decision making competent adolescents. In that connection, note that people with mental retardation are at an increased risk of developing emotional disorders [66]. Higher percentages of mild mental retardation are reported in boys, whereas the ratio differences are less obvious in people with severe and profound mental retardation. The results in our study are in accordance with results of international studies, where boys prevail in the appearance of mental retardation for the abovementioned reasons $[67,68]$.

$10,2 \%$ of adolescents (10,2\% boys, $0 \%$ girls) belonged to the F80-F89 category. In our study group, adolescents with a developmental disorder were in a therapeutic relationship with a specialist in the outpatient clinic. They themselves feel their peculiarity and are usually open to the family's urging towards psychotherapy. to improve their social and communicative skills and acceptance by peers. The 
fact that in our study group all the adolescents presenting with developmental disorder were boys, is in agreement with international epidemiological data, where pervasive developmental disorders are more often in boys, with a sex ratio of boys to girls from 3,5-4 to 1 [69] [38].

$4,1 \%$ ( $0 \%$ girls, $4,1 \%$ boys) belonged to the F90-F99 category. Conduct disorder is usual in childhood and adolescence and it is more common in boys than girls with a ratio varying from 4:1 to $12: 1$, something also appearing in our own percentages, since only boys were in therapy with conduct disorder [70, 71].

\section{Limitations and strengths}

While other studies conducted large-scale surveys of child and adolescent psychiatric disorders using random and population representative sample of adolescents (i.e. school-based or non-school studies), we focused on adolescents with mental disorders who, however, maintained their ability to engage in shared decision making and already were in treatment engagement. For that reason, our study participants number was limited. However, the fact that we exclusively included decision making competent adolescents with mental disorders who were stably engaged in psychotherapy is a strength of this study.

\section{Conclusions}

The largest part of adolescents (44,9\%) were found to suffer from mood (affective) disorders, while 20,4\% suffered from neurotic disorders. Pessimism $(32,7 \%)$, reduction of energy $(28,6 \%)$ and difficulty in concentration $(32,7 \%)$ were found in high frequency. $22,4 \%$ of adolescents complained of sleep disorders. However, limited interest in sex was noted, which came in contrast with international and Greek data, where interest and experimentation around sex seems to preoccupy an essential percentage of adolescents. Furthermore, sleep disorders, either as a symptom of an underlying disease, or as an independent clinical condition, seem to preoccupy adolescents and this may be a motive for their treatment engagement. For the most part, the findings enhanced prior studies which, however, did not exclusively include decision competent adolescents with mental disorders who were engaged in psychotherapy (for at least two months). Interestingly, however, we identified some nuances related to interest in sex and sleep disorders. Further research is recommended for the investigation of possible correlations between the lack of interest in sex or sleep disorders and the fact that the adolescents of our sample were decision making competent and engaged in psychotherapy.

\section{Abbreviations}

BDI=Beck Depression Inventory

DMC $=$ Decision Making Capacity

$I C D=$ International Classification of. Diseases 
PD= Personality Disorders

SDs= Standard Deviation score

SDM = Shared decision-making

WISC=Wechsler Intelligence Scale for Children

\section{References}

1. World Health Assembly Update, 25 May 2019. Available from: https://www.who.int/news/item/2505-2019-world-health-assembly-update (last access: 24 February 2021).

2. Radoilska, L. Autonomy and Mental Disorder Oxford: Oxford University Press, 2012, 328pp 2, DOI: $10.1093 / \mathrm{med} / 9780199595426.001 .0001$

3. Widdershoven GAM, Ruissen A, van Balkom AJLM, et al. Competence in chronic mental illness: the relevance of practical wisdom Journal of Medical Ethics 2017; 43:374-378. http://dx.doi.org/10.1136/medethics-2014-102575

4. Friedman M. Autonomy, Gender, Politics Oxford: Oxford University Press, 2003. Print. DOI:10.1093/0195138503.001.0001

5. Hermann H, Trachsel M, Elger BS, Biller-Andorno N. Emotion and Value in the Evaluation of Medical Decision-Making Capacity: A Narrative Review of Arguments. Front Psychol. 2016 May 26;7:765. doi: 10.3389/fpsyg.2016.00765.

6. World Health Organization. Adolescent health. Available from: https://www.who.int/healthtopics/adolescent-health/\#tab=tab_1 (last access: 24 February 2021).

7. Hartley CA, Somerville LH. The neuroscience of adolescent decision-making. Curr Opin Behav Sci. 2015;5:108-115. https://doi.org/10.1016/j.cobeha.2015.09.004

8. Santelli, J., Rogers, A., Rosenfeld, W., DuRant, R., Dubler, N., Morreale, M., English, A., Lyss, S, Wimberly, Y. and Schissel, A. (2003). Guidelines for Adolescent Health Research: A position paper of the Society for Adolescent Medicine. The Journal of adolescent health: official publication of the Society for Adolescent Medicine. 33. 396-409. DOI: https://doi.org/10.1016/j.jadohealth.2003.06.009

9. Katz AL, Webb SA, AAP COMMITTEE ON BIOETHICS. Informed Consent in Decision-Making in Pediatric Practice. Pediatrics. 2016;138(2):e20161485 DOI: https://doi.org/10.1542/peds.2016-1485

10. Roberson AJ, Kjervik DK. Adolescents' perceptions of their consent to psychiatric mental health treatment. Nurs Res Pract. 2012; 2012: 379756. https://doi.org/10.1155/2012/379756

11. Larcher V. Consent, competence, and confidentiality. BMJ. 2005;330(7487):353-356. doi: https://doi.org/10.1136/bmj.330.7487.353

12. Miller VA. Involving Youth With a Chronic Illness in Decision-making: Highlighting the Role of Providers. Pediatrics. 2018;142(Suppl 3):S142-S148. DOI: https://doi.org/10.1542/peds.2018-0516D 
13. Sibley A, Pollard AJ, Fitzpatrick R, Sheehan M. Developing a new justification for assent. BMC Med Ethics. 2016;17:2. https://doi.org/10.1186/s12910-015-0085-x

14. Grootens-Wiegers $P$, Hein IM, van den Broek JM, de Vries MC. Medical decision-making in children and adolescents: developmental and neuroscientific aspects. BMC Pediatr. 2017;17(1):120. DOI https://doi.org/10.1186/s12887-017-0869-x

15. Dickens B, Cook RJ. Adolescents and Consent to Treatment. International Journal of Gynecology and Obstetrics, 2005; 89: 179-184 (https://doi.org/10.1016/j.ijgo.2005.01.038). U Toronto Legal Studies Research Paper No. 14-05, Available from SSRN:https://ssrn.com/abstract=862384 (last access: 9 Sept 2020).

16. Hein IM, De Vries MC, Troost PW, Meynen G, Van Goudoever JB, Lindauer RJ. Informed consent instead of assent is appropriate in children from the age of twelve: Policy implications of new findings on children's competence to consent to clinical research. BMC Med Ethics. 2015;16(1):76. DOI https://doi.org/10.1186/s12910-015-0067-z

17. Parekh, S.A. (2006) 'Child consent and the law: an insight and discussion into the law relating to consent and competence', Child: Care, Health and Development, 33(1), pp. 78-82. https://doi.org/10.1111/j.1365-2214.2006.00641.x

18. Schwartz Y, Williams TS, Roberts SD, Hellmann J, Zlotnik Shaul R. Adolescent decision-making in Canadian medical contexts: Integrating neuroscience and consent frameworks. Paediatr Child Health. 2018;23(6):374-376. https://doi.org/10.1093/pch/pxy037

19. Oetzel, K.B. and Scherer, D.G. Therapeutic Engagement With Adolescents in Psychotherapy. (2003). Psychotherapy Theory Research \& Practice 40(3):215-225. https://doi.org/10.1037/00333204.40.3.215

20. World Health Organization. Adolescent mental health-Mapping actions of nongovernmental organizations and other international development organizations. WHO World Heal Organ. $2012 ; 50$.

21. Bremberg S. Mental health problems are rising more in Swedish adolescents than in other Nordic countries and the Netherlands. Acta Paediatr. 2015 Oct;104(10):997-1004. https://doi.org/10.1111/apa.13075

22. Achenbach TM, Rescorla LA, Ivanova MY. International epidemiology of child and adolescent psychopathology I: diagnoses, dimensions, and conceptual issues. J Am Acad Child Adolesc Psychiatry 2012; 51:1261-1272. DOI: https://doi.org/10.1016/j.jaac.2012.09.010

23. Rescorla L, Ivanova MY, Achenbach TM, et al. International epidemiology of child and adolescent psychopathology ii: integration and applications of dimensional findings from 44 societies. $\mathrm{J} A m$ Acad Child Adolesc Psychiatry 2012; 51:1273-1283.e1278. DOI: https://doi.org/10.1016/j.jaac.2012.09.012

24. Karow A, Bock T, Naber D, Löwe B, Schulte-Markwort M, Schäfer I, Gumz A, Degkwitz P, Schulte B, König HH, Konnopka A, Bauer M, Bechdolf A, Correll C, Juckel G, Klosterkötter J, Leopold K, Pfennig A, Lambert M. Die psychische Gesundheit von Kindern, Jugendlichen und jungen Erwachsenen-Teil 2: Krankheitslast, Defizite des deutschen Versorgungssystems, Effektivität und Effizienz von "Early 
Intervention Services" [Mental health of children, adolescents and young adults--part 2: burden of illness, deficits of the German health care system and efficacy and effectiveness of early intervention services]. Fortschr Neurol Psychiatr. 2013 Nov;81(11):628-38. DOI: 10.1055/s-0033-1355840 [in German].

25. Polanczyk GV, Salum GA, Sugaya LS, Caye A, Rohde LA. Annual research review: A meta-analysis of the worldwide prevalence of mental disorders in children and adolescents. J Child Psychol Psychiatry. 2015 Mar;56(3):345-65. https://doi.org/10.1111/jcpp.12381

26. Erskine HE, Baxter AJ, Patton G, Moffitt TE, Patel V, Whiteford HA, Scott JG. The global coverage of prevalence data for mental disorders in children and adolescents. Epidemiol Psychiatr Sci. 2017 Aug;26(4):395-402. DOI: https://doi.org/10.1017/S2045796015001158

27. Laufer M. (transl. Tsianti V.) Adolescent disturbance and breakdown, Athens: Kastaniotis, 1992, pp: 18 et seq. [in Greek].

28. Hayes, D., Edbrooke-Childs, J., Town, R. et al. Barriers and facilitators to shared decision making in child and youth mental health: clinician perspectives using the Theoretical Domains Framework. Eur Child Adolesc Psychiatry 2019; 28: 655-666. DOI https://doi.org/10.1007/s00787-018-1230-0

29. Hayes D, Fleming I, Wolpert M. Developing safe care in mental health for children and young people: drawing on UK experience for solutions to an under-recognised problem. Curr Treat Options Pediatr 2015; 1:309-319. DOI https://doi.org/10.1007/s40746-015-0037-1

30. Warnick EM, Bearss K, Weersing VR, Scahill L, Woolston J. Shifting the treatment model: impact on engagement in outpatient therapy. Adm Policy Ment Health. 2014 Jan;41(1):93-103. DOI https://doi.org/10.1007/s10488-012-0439-3

31. Georgas D. Paraskeuopoulos, I., Mpezevegkis H., \& Giannitsas, N.D. (1997) Greek WISC-III: Examiner Quide, Athens: Ellinika Grammata.

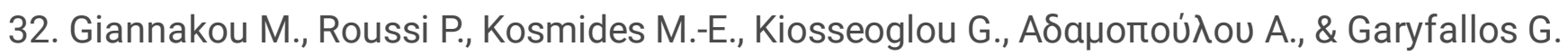
Adaptation of the Beck Depression Inventory-ii to Greek population, Hellenic Journal of Psychology,Vol. 10(2013), pp 120-146. [in Greek].

33. Hoare E, Jacka F, Berk M. The impact of urbanization on mood disorders: an update of recent evidence. Curr Opin Psychiatry. 2019 May;32(3):198-203. doi: 10.1097/YC0.0000000000000487.

34. Odone A, Landriscina T, Amerio A, Costa G. The impact of the current economic crisis on mental health in Italy: evidence from two representative national surveys. Eur J Public Health. 2018 Jun 1;28(3):490-495. doi: 10.1093/eurpub/ckx220.

35. Economou M, Peppou L, Fousketaki S, Theleritis Ch, Patelakis A, Alexiou T, Madianos M, Stefanis C. [Economic crisis and mental health: effects on the prevalence of common mental disorders]. Psychiatriki. 2013 Oct-Dec;24(4):247-61. Greek, Modern. PMID: 24486974.

36. Bor W, Dean AJ, Najman J, Hayatbakhsh R. Are child and adolescent mental health problems increasing in the 21st century? A systematic review. Aust N Z J Psychiatry. 2014 Jul;48(7):606-16. 
doi: $10.1177 / 0004867414533834$.

37. West P. and Sweeting H. Fifteen, female and stressed: changing patterns of psychological distress over time. Journal of Child Psychology and Psychiatry 2003 44: 399-411. doi: 10.1111/1469-7610.00130. PMID: 12635969.

38. Kuehner $\mathrm{C}$. Why is depression more common among women than among men? Lancet Psychiatry. 2017 Feb;4(2):146-158. doi: 10.1016/S2215-0366(16)30263-2.

39. Slavich GM, Sacher J. Stress, sex hormones, inflammation, and major depressive disorder: Extending Social Signal Transduction Theory of Depression to account for sex differences in mood disorders. Psychopharmacology (Berl). 2019 Oct;236(10):3063-3079. doi: 10.1007/s00213-019-05326-9.

40. Krauss H, Buraczyńska-Andrzejewska B, Piątek J, Sosnowski P, Mikrut K, Głowacki M, Misterska E, Żukiewicz-Sobczak W, Zwoliński J. Occurrence of neurotic and anxiety disorders in rural schoolchildren and the role of physical exercise as a method to support their treatment. Ann Agric Environ Med. 2012;19(3):351-6. PMID: 23020023.

41. Ravens-Sieberer U, Otto C, Kriston L, Rothenberger A, Döpfner M, Herpertz-Dahlmann B, Barkmann C, Schön G, Hölling H, Schulte-Markwort M, Klasen F. The longitudinal BELLA study: design, methods and first results on the course of mental health problems. Eur Child Adolesc Psychiatry. 2015;24(6):651-663. DOI https://doi.org/10.1007/s00787-014-0638-4

42. Seeley JR, Kosty DB, Farmer RF, Lewinsohn PM. The modeling of internalizing disorders on the basis of patterns of lifetime comorbidity: associations with psychosocial functioning and psychiatric disorders among first-degree relatives. J Abnorm Psychol. 2011;120(2):308-321. doi:10.1037/a0022621

43. Tiller JW. Depression and anxiety. Med J Aust. 2013 Sep 16;199(S6):S28-31. doi: $10.5694 / \mathrm{mja} 12.10628$.

44. Choi KW, Kim YK, Jeon HJ. Comorbid Anxiety and Depression: Clinical and Conceptual Consideration and Transdiagnostic Treatment. Adv Exp Med Biol. 2020;1191:219-235. doi: 10.1007/978-981-329705-0_14.

45. Gowers, S.G., Crisp, A.H., Joughin, N. and Bhat, A. (1991), Premenarcheal Anorexia Nervosa. Journal of Child Psychology and Psychiatry, 32: 515-524. https://doi.org/10.1111/j.14697610.1991.tb00328.x

46. Beck, D., Casper, R. \& Andersen, A., 1996. Truly late onset of eating disorders: a study of 11 cases averaging 60 years of age at presentation. International Journal of Eating Disorders, pp. 20:389395.

https://doi.org/10.1002/(SICI)1098-108X(199612)20:4<389::AID-EAT6>3.0.C0;2-J 
47. Sparti C, Santomauro D, Cruwys T, Burgess P, Harris M. Disordered eating among Australian adolescents: Prevalence, functioning, and help received. Int J Eat Disord. 2019 Mar;52(3):246-254.

48. Flament MF, Buchholz A, Henderson K, Obeid N, Maras D, Schubert N, Paterniti S, Goldfield G. Comparative distribution and validity of DSM-IV and DSM- 5 diagnoses of eating disorders in adolescents from the community. Eur Eat Disord Rev. 2015;23(2):100-110.

49. Herpertz-Dahlmann B. Adolescent eating disorders: update on definitions, symptomatology, epidemiology, and comorbidity. Child Adolesc Psychiatr Clin N Am. 2015 Jan;24(1):177-96.

50. Braconnier A., Marcelli D. [The thousand faces of adolescence]. Athens: Kastaniotis, 2002, pp: 30 et seq. [in Greek]

51. Kansagra S. Sleep Disorders in Adolescents. Pediatrics. 2020 May;145(Suppl 2):S204-S209.

52. Van Dyk TR, Becker SP, Byars KC. Rates of Mental Health Symptoms and Associations With SelfReported Sleep Quality and Sleep Hygiene in Adolescents Presenting for Insomnia Treatment. J Clin Sleep Med. 2019 Oct 15;15(10):1433-1442.

53. Hysing M, Harvey AG, Linton SJ, Askeland KG, Sivertsen B. Sleep and academic performance in later adolescence: results from a large population-based study. J Sleep Res. 2016 Jun;25(3):318-24.

54. Zhang L, Yang Y, Liu ZZ, Jia CX, Liu X. Sleep disturbance mediates the association between intrafamily conflict and mental health problems in Chinese adolescents. Sleep Med. 2018 Jun;46:7480 .

55. Reynolds MA, Herbenick DL. Using computer-assisted self-interview (CASI) for recall of childhood sexual experiences. In: Bancroft J, editor. Sexual Development in Childhood. Bloomington IN: Indiana University Press; 2003. pp. 77-81.

56. Efrati Y, Dannon P. Normative and Clinical Self-Perceptions of Sexuality and Their Links to Psychopathology among Adolescents. Psychopathology. 2018;51(6):380-389.

57. Schalet A. Must we fear adolescent sexuality? Medscape General Medicine. 2004;6(4):44. 6, 44-44.

58. Fortenberry JD. Puberty and adolescent sexuality. Horm Behav. 2013 Jul;64(2):280-7.

59. McClain Z, Peebles R. Body Image and Eating Disorders Among Lesbian, Gay, Bisexual, and Transgender Youth. Pediatr Clin North Am. 2016 Dec;63(6):1079-1090.)

60. Tsitsika A. Sexuality and Adolescence (2014). Adolescent Health Unit, B' Pediatric Clinic of Athens University, the Athens General Children's Hospital "Pan. \& Aglaia Kyriakou”, Available from: youthhealth.gr (last access: 24 February 2021). [in Greek]. 
61. Fernandes LC, Gillberg Cl, Cederlund M, Hagberg B, Gillberg C, Billstedt E. Aspects of Sexuality in Adolescents and Adults Diagnosed with Autism Spectrum Disorders in Childhood. J Autism Dev Disord. 2016 Sep;46(9):3155-65.

62. Schöttle D, Briken P, Tüscher O, Turner D. Sexuality in autism: hypersexual and paraphilic behavior in women and men with high-functioning autism spectrum disorder. Dialogues Clin Neurosci. 2017 Dec;19(4):381-393.

63. 63. Papageorgiou B.A.. Child and Adolescent Psychiatry. Thessaloniki: University Studio Press, 2005, pp: 128,242 et seq. [in Greek].

64. Feenstra DJ, Hutsebaut J. De prevalentie, ziektelast, structuur en behandeling van persoonlijkheidsstoornissen bij adolescenten [The prevalence, burden, structure and treatment of personality disorders in adolescents]. Tijdschr Psychiatr. 2014;56(5):319-25. Dutch. PMID: 24838586.

65. Schulte Holthausen B, Habel U. Sex Differences in Personality Disorders. Curr Psychiatry Rep. 2018 Oct 11;20(12):107. doi: 10.1007/s11920-018-0975-y. PMID: 30306417.

66. Borthwick-Duffy SA. Epidemiology and prevalence of psychopathology in people with mental retardation. J Consult Clin Psychol. 1994 Feb;62(1):17-27. doi: 10.1037//0022-006x.62.1.17. PMID: 8034819.

67. Panek PE, Jungers MK. Effects of age, gender, and causality on perceptions of persons with mental retardation. Res Dev Disabil. 2008 Mar-Apr;29(2):125-32. doi: 10.1016/j.ridd.2007.01.002. Epub 2007 Mar 7. PMID: 17346926.

68. Ayoglu FN, Cabuk F, Kiran S, Ocakci A, Sahin Z, Dursun A. The prevalence of mental retardation by gender, age of diagnosis and location in Zonguldak province, Turkey. Neurosciences (Riyadh). 2008 Jan;13(1):57-60. PMID: 21063288.

69. Fombonne E. Epidemiological surveys of autism and other pervasive developmental disorders: an update. J Autism Dev Disord. 2003 Aug;33(4):365-82. doi: 10.1023/a:1025054610557.

70. Szentiványi D, Halász J, Horváth LO, Kocsis P, Miklósi M, Vida P, Balázs J. [Quality of life of adolescents with conduct disorder: gender differences and comorbidity with oppositional defiant disorder]. Psychiatr Hung. 2019;34(3):280-286. Hungarian. PMID: 31570659.

71. Mohan L, Yilanli M, Ray S. Conduct Disorder. [Updated 2020 Nov 19]. In: StatPearls [Internet]. Treasure Island (FL): StatPearls Publishing; 2021 Jan-. Available from: https://www.ncbi.nlm.nih.gov/books/NBK470238/

\section{Supplementary Files}


This is a list of supplementary files associated with this preprint. Click to download.

- ADDITIONALFILE1.doc

- ADDITIONALFILE2.doc 